\title{
Knowledge and Skills Needed by Teachers in Chinese Agricultural Schools Regarding Curriculum and Instruction Reforms
}

\author{
Xiaorong Shao \\ Research Associate \\ 415 Agricultural Administration Building \\ Pennsylvania State University \\ University Park, PA, 16802 \\ E-mail: xzs100@psu.edu \\ Thomas Bruening \\ Associate Professor \\ Agricultural and Extension Education Department \\ 335 Agricultural Administration Building \\ Penn State University \\ University Park, PA, 16802 \\ E-mail: Tbruening@psu.edu
}

\begin{abstract}
Agricultural schools in China have undergone numerous transitions as the system is shifting from non-effective academic institutions to vocational-oriented education brought by China's economic reforms during the past two decades. Changes of traditional curricular and instructional methods have been recognized as an important strategy to strengthen vocational offerings of the existing agricultural educational system. The purpose of this study was to examine teachers' current and desired knowledge and skills related to curriculum and instruction. The population for the study was teachers of 12 agricultural schools in China. A systematic randomization resulted in a sample of 398 participants from the population. A survey questionnaire was constructed and used to collect data from randomly selected teachers. The results showed that teachers indicated a significantly lower level of current knowledge and skill and they desired to have a higher level of knowledge and skills regarding curriculum and instruction. Teachers also indicated that they were particularly in lack of expertise in educational technology and curriculum and innovative teaching. Based on the results from this study, a need for teacher training and professional development is evident at these 12 schools. It is strongly recommended that teachers should be given opportunities and support to attend teacher training and professional development programs, which will increase their current knowledge base and enable them to successfully implement curriculum innovations.
\end{abstract}

Keywords: Chinese Agricultural Schools, Curriculum and Instruction Reforms, Knowledge and Skills of Teachers, Teachers Professional Development Programs 


\section{Introduction/Background}

A major transition in agricultural schools in China is underway as the system is shifting from non-effective academic institutions to vocational-oriented education brought by China's economic reforms. Changes in traditional curricular and instructional methods have been recognized as an important strategy to strengthen vocational offerings of the existing agricultural educational system (Ministry of Education, 1998).

In the past, agricultural schools were academic institutions classified as secondary specialized schools. These schools taught a curriculum that was general in nature and the theory taught was quasi vocational. As a result of China's economic reform movement, a mismatch of teaching strategies and curricula to meet the needs of the new economic realities has become evident in Chinese agricultural education (Chen, 2000). In response, agricultural schools have been tried to focus on practical training and job-related skills for students in vocational agriculture since 1990s. In addition, the reform efforts have been strengthened by the information obtained from educational systems outside China. Modular teaching approach, competencybased education, and student-centered instruction have been tried in some schools with the support from the Ministry of Agriculture in China and the Food and Agriculture Organization of United Nations (Weng, 1998).

Teachers have been identified as key players in this educational transformation. Traditionally, agricultural teachers were not required to be certified in teaching, and therefore most of them lacked systematic education in pedagogical knowledge and instructional methodology. This problem has aggravated the changes agricultural schools would like to implement. If systematic professional development of teachers is not addressed it will be challenging to move the reform movement forward (Chen, 2000). To sustain the reform efforts, building the skills of teachers to implement the new curriculum is a high priority with educational leaders at local, provincial, and national levels. What kind of attitudes, knowledge, and skills do teachers need to deal with the changes within local schools? What areas need to be addressed for teacher training and professional development? These questions have become central to the debate among all individuals involved.

\section{Theoretical Framework}

Curriculum has been considered an essential element for all schooling. Thus, when attempts are made to initiate reforms of the educational system, changes in curriculum have to be a starting point. As Kelly (1982) indicated, changes in the structure of the school system should be followed by attempts to make corresponding modifications to the curriculum. Without curriculum change, modifications to the structure of the system make little sense. Therefore, the reform of curriculum is essential to the formation of a new vocational educational system, as the curriculum is viewed as a basic element for overall educational changes (Weng, 1998).

Among different models of curriculum development, the Objectives Model has been considered a common approach. Having been developed and reformed in one form or another over many years, the major steps involved in the Objectives Model approach, summarized by Taylor (2000), are as follows:

- Conduct a situation analysis, diagnosing educational and training needs,

- Formulate aims for each level required; and allocate time,

- Formulate objectives for each level required (subject, unit, lesson etc.),

- Select the content of the teaching/training (i.e. what is to be taught),

- Devise teaching/training methods and learning experiences, 
- Organize learning experiences; and allocate time for these,

- Develop assessment instruments. Taylor (2000) also indicated that we all live in a changing society, in which new knowledge is constantly being discovered and old knowledge proved wrong. Policies, educational purposes and structures are also constantly changed. Curriculum planning therefore needs to be a continuous, open, and participative process.

Erickson (2001, p.3) noted, "the rapid changes occurring in the workplace are affecting the curriculum of vocational school programs by emphasizing problem solving, teamwork, and the use of technology in conjunction with "real-world" simulations and experiences." Thus, educators should be willing to explore the connections between school and workplace and make learning more practical and meaningful.

In an effort to justify areas for future research in vocational education, Copa and Bentley (1992) indicated that technological change, global interdependence, and changing economic and social conditions and values resulted in the need for the continuous changes in the content of vocational education. How can these changes best be monitored and translated into an effective curriculum for vocational education? Attention needs to be given to strategies for content identification as well as curriculum change.

In another paper, Copa (1992) indicated that the reforms of vocational education appeared to be connected with curriculum development, evaluation and assessment, teaching methods, and teacher training. He stressed that career and technical education (CTE) teachers should be able to utilize various learning situations and different teaching methods effectively to accommodate different learning styles. Teachers also need to employ the most effective approaches to incorporate academic subject into their CTE programs. In addition, CTE teachers need to work with academic teachers to facilitate a better understanding of the bond between theoretical information and its application.

\section{Purpose and Objectives}

The purpose of this study was to examine teachers' current and desired knowledge and skills related to curriculum development and instructional methods in Chinese agricultural schools. The objectives were to:

- Describe the demographics of teacher respondents;

- Describe teachers' current and desired knowledge and skills regarding curriculum and instruction; and

- Identify major knowledge and skills gaps related to curriculum and instruction.

\section{Methods and Procedures Population and Sample}

The population for this study was teachers from 12 agricultural schools in China. These schools were selected since they were part of the reform efforts supported by the Ministry of Agriculture and the Agriculture and Food Organization of United Nations during 1994 to 2000. The total number of teachers in 12 schools was 1,299. A systematic random sampling technique was used to select teachers from each school. Every third teacher from the official teaching roster was selected, which yielded a sample size of 398 participants (Cochran, 1977).

Instrument Development and Testing

A survey questionnaire was employed to collect data from the selected teachers. The questionnaire was constructed based on an extensive literature review as well as researchers' experience with the system. Forty items were developed to document teachers' current knowledge/skills and desired knowledge/skills related to curriculum and instruction. Teachers' selfreported current and desired 
knowledge/skills were rated using the scale: $0=$ none, $1=$ low, $2=$ average, $3=$ high .

The questionnaire was translated into Chinese and validated by the agricultural educators both in China and the United States. The reliability was established through a pilot study in China. Several minor revisions were made to the questionnaire immediately after the pilot test. The reliability of the Cronbach's coefficient alpha for teachers' current knowledge/skills and desired knowledge/skills related to curriculum and instruction were 0.92 and 0.81 respectively. Survey Administration

Surveys were mailed to 12 participant schools through a contact person in each school. A follow-up phone call to each contact person was made a week after the survey was distributed. The call was completed to further direct the process of participant selection and to provide survey administration. There were 398 questionnaires sent with 350 returned. The response rate was $88 \%$.

Data Analysis

Data were input and analyzed using the Statistical Package for Social Science (SPSS). Both descriptive and inferential statistics were used to summarize data.

\section{Findings/Results}

Demographic Information on Respondents

The total number of teacher

respondents was 350 . The average age of teachers was 38 years old, with 14 years of work experience and 13 years of teaching experience. The majority of the respondents (61\%) were male. Eighty-three percent of teachers responding were bachelor degree holders and only $17 \%$ had other educational preparation backgrounds.

Forty-four percent of the teachers were lecturers, $33 \%$ were senior lecturers and $22 \%$ were assistant lecturers. A substantial proportion of the respondents
(70\%) taught agricultural subjects, 29\% taught academic subjects, and 1\% taught both vocational and academic subjects.

\section{Current Knowledge/Skills and Desired} Knowledge/Skills of Respondents

Forty items were included in the instrument to gather teachers' current knowledge/skills and desired knowledge/skills related to curriculum and instruction reforms. To perform inferential statistics, these 40 items were grouped into six categories according to the nature of each subscale measured.

\section{Current Knowledge/Skills of Respondents}

Results in table 1 showed that mean values of teachers' current knowledge/skills ranged from 1.30 to 2.41 ("low" to "average"). The respondents tended to perceive a "low" level of knowledge/skills in five items: field trip $(M=1.48)$, role play $(M=1.49)$, computer-assisted instruction $(M$ $=1.38)$, using computers in teaching $(M=$ $1.30)$, and using multimedia aids $(M=1.30)$. They reported an "average" level of knowledge/skills in organizing student projects $(M=1.50)$, group projects $(M=$ $1.59)$, curriculum development models $(M=$ $1.60)$, modular teaching approach $(M=$ $1.65)$, cooperative learning $(M=1.69)$, debate $(M=1.71)$, oral presentations $(M=$ $1.75)$, measurable objectives writing $(M=$ $1.71)$, and individualizing teaching $(M=$ 1.73).

The respondents tended to report better current knowledge/skills in developing written tests $(M=2.36)$, writing teaching plans $(M=2.30)$, managing a classroom $(M=2.41)$, lecture $(M=2.46)$, motivating students to learn $(\mathrm{M}=2.24)$, demonstration $(M=2.24)$, and preparing teaching materials $(M=2.23)$, although these items still fell into the scale of "average" level. 
Table 1

Means and Standard Deviations of Current and Desired Knowledge/Skills

\begin{tabular}{|c|c|c|c|c|c|c|}
\hline \multirow[b]{3}{*}{ Item } & \multicolumn{6}{|c|}{ Knowledge/Skills } \\
\hline & \multicolumn{3}{|c|}{ Current } & \multicolumn{3}{|c|}{ Desired } \\
\hline & $n$ & $M$ & $S D$ & $n$ & $M$ & $S D$ \\
\hline \multicolumn{7}{|l|}{ Planning and Management } \\
\hline Writing a syllabus & 338 & 1.97 & .71 & 337 & 2.80 & .43 \\
\hline Writing teaching plans & 337 & 2.30 & .51 & 338 & 2.83 & .44 \\
\hline Preparing teaching materials & 332 & 2.23 & .69 & 331 & 2.83 & .42 \\
\hline Conducting student internship programs & 296 & 2.12 & .78 & 302 & 2.71 & .57 \\
\hline Managing a classroom & 334 & 2.41 & .58 & 337 & 2.85 & .39 \\
\hline Managing a laboratory & 327 & 2.04 & .85 & 329 & 2.73 & .64 \\
\hline \multicolumn{7}{|l|}{ Curriculum and Innovative teaching } \\
\hline Motivating students to learn & 335 & 2.24 & .60 & 337 & 2.85 & .41 \\
\hline Adopting modular teaching approach & 339 & 1.65 & .81 & 339 & 2.60 & .65 \\
\hline Conducting experiential learning activities & 339 & 1.86 & .78 & 337 & 2.69 & .54 \\
\hline Organizing cooperative learning & 335 & 1.69 & .78 & 333 & 2.67 & .55 \\
\hline Knowledge of curriculum development models & 336 & 1.60 & .77 & 333 & 2.65 & .56 \\
\hline Developing student leadership skills & 339 & 1.89 & .70 & 337 & 2.71 & .52 \\
\hline Developing students' problem-solving skills & 335 & 2.16 & .66 & 334 & 2.84 & .40 \\
\hline \multicolumn{7}{|l|}{ Competency-Based Education } \\
\hline Writing measurable objectives & 336 & 1.71 & .86 & 336 & 2.64 & .59 \\
\hline Basing teaching upon tasks analysis & 335 & 1.84 & .78 & 335 & 2.71 & .53 \\
\hline Conducting performance-based activities & 337 & 1.93 & .72 & 337 & 2.73 & .49 \\
\hline Conducting work-based contextual learning & 337 & 1.80 & .80 & 337 & 2.67 & .56 \\
\hline Individualizing teaching & 335 & 1.73 & .88 & 335 & 2.65 & .58 \\
\hline Offering timely feedback & 336 & 2.16 & .72 & 336 & 2.81 & .44 \\
\hline Using criterion-reference assessment & 336 & 1.93 & .76 & 336 & 2.64 & .58 \\
\hline \multicolumn{7}{|l|}{ Teaching Methods and Activities } \\
\hline Lecture & 328 & 2.46 & .55 & 331 & 2.82 & .43 \\
\hline Discussion & 329 & 2.02 & .66 & 333 & 2.73 & .51 \\
\hline Demonstration & 331 & 2.24 & .68 & 332 & 2.81 & .44 \\
\hline Case study & 327 & 1.94 & .79 & 330 & 2.69 & .57 \\
\hline Group projects & 324 & 1.59 & .80 & 328 & 2.59 & .63 \\
\hline Field trip & 324 & 1.48 & .99 & 327 & 2.55 & .72 \\
\hline Role play & 326 & 1.49 & .94 & 328 & 2.52 & .68 \\
\hline Problem-solving & 330 & 2.08 & .71 & 332 & 2.79 & .45 \\
\hline Debate & 323 & 1.71 & .81 & 325 & 2.56 & .68 \\
\hline Oral presentations & 326 & 1.75 & .92 & 328 & 2.59 & .68 \\
\hline
\end{tabular}


Table 1 (continued)

\begin{tabular}{lcccccc}
\hline & \multicolumn{5}{c}{ Knowledge/Skills } \\
\cline { 2 - 7 } Item & \multicolumn{5}{c}{ Current } & \multicolumn{4}{c}{ Desired } \\
\cline { 2 - 7 } & $n$ & $M$ & $S D$ & $n$ & $M$ & $S D$ \\
\hline Evaluation and Assessment & & & & & & \\
$\quad$ Written test & 330 & 2.36 & .57 & 333 & 2.74 & .50 \\
Practical test & 329 & 2.26 & .72 & 332 & 2.82 & .49 \\
Oral test & 327 & 1.83 & .85 & 330 & 2.58 & .65 \\
Student projects & 325 & 1.50 & .92 & 327 & 2.46 & .72 \\
Essays & 321 & 2.07 & .80 & 323 & 2.62 & .61 \\
Skill test & 327 & 2.18 & .78 & 328 & 2.79 & .54 \\
Performance observation & 323 & 2.04 & .74 & 325 & 2.69 & .54 \\
$\quad$ Attitude test & 328 & 2.03 & .70 & 331 & 2.68 & .55 \\
Educational Technology & & & & & & \\
Computer-assisted instruction & 329 & 1.38 & .95 & 332 & 2.57 & .68 \\
$\quad$ Using computers in teaching & 334 & 1.30 & 1.01 & 336 & 2.54 & .79 \\
Using multimedia aids & 335 & 1.30 & 1.04 & 336 & 2.53 & .78 \\
\hline
\end{tabular}

Note. Scale: $0=$ none, $1=$ low, $2=$ average, $3=$ high; low $\leq 1.5 ;<1.5$ average $<2.5 ;$ high $\geq 2.5$.

Desired Knowledge/Skills of Respondents

Overall, the respondents tended to report a "high" level of desired knowledge/skills related to curriculum and instruction reforms in all 40 items. The mean values were within the range of 2.52 to 2.85 and showed little fluctuation among 40 items.

Many of the respondents desired to have a higher level of knowledge/skills in common practices regarding teaching and learning. These items were: writing teaching plans $(M=2.83)$, preparing teaching materials $(M=2.83)$, lecture $(M=2.82)$, demonstration $(M=2.81)$, practical testing $(M=2.82)$, motivating students to learn $(M$ $=2.85)$, managing a classroom $(M=2.85)$, offering timely feedback $(M=2.81)$, and developing students' problem-solving skills $(M=2.84)$.

\section{Differences in Current versus Desired} Knowledge/Skills of Respondents

A paired t-test was performed to examine the differences between current knowledge/skills and desired knowledge/skills of respondents regarding curriculum and instruction in six categories.
Table 2 presents means, standard deviations, paired t-test results, and Cohen's d effect size between teachers' current and desired knowledge/skills regarding curriculum and instruction.

Paired t-test results revealed that current knowledge/skills of respondents were significantly different from desired knowledge/skills $(p<0.001)$. The respondents rated their desired knowledge/skills were significantly higher than the current knowledge/skills in all six categories.

The general guidelines for analyzing effect size developed by Cohen (1988) were used to determine the practical significance between current and desired knowledge/skills for each category. The effect size (Cohen's d) was determined according to the following Cohen's guidelines:

Less than .20: Very small or little effect .20-.49: Small effect size .50-.79: Medium or moderate effect size .80 or more: Large effect size 
The results revealed that all six categories had "large" effect size between current knowledge/skills level and desired knowledge/skills level (see Table 2). The category of evaluation and assessment had the lowest effect size value $($ C.d. $=1.41)$ while curriculum and innovative teaching was showed the highest effect size value $(C . d .=2.00)$ among six categories.

Table 2

Means, Standard Deviations, Paired t-Test Results and Cohen's d Effect Size regarding Current and Desired Knowledge/Skills

\begin{tabular}{|c|c|c|c|c|c|c|c|c|}
\hline \multirow[b]{3}{*}{ Category } & \multicolumn{5}{|c|}{ Knowledge/Skills } & \multirow[b]{3}{*}{$t$} & \multirow[b]{3}{*}{$p$} & \multirow{3}{*}{$\begin{array}{l}\text { Cohen's } d \\
\text { Effect size }\end{array}$} \\
\hline & \multicolumn{3}{|c|}{ Current } & \multicolumn{2}{|c|}{ Desired } & & & \\
\hline & $n$ & $M$ & $S D$ & $M$ & $S D$ & & & \\
\hline Planning and management & 279 & 2.18 & 0.44 & 2.80 & 0.31 & 23.00 & $<.001$ & 1.65 \\
\hline $\begin{array}{l}\text { Curriculum and innovative } \\
\text { teaching }\end{array}$ & 312 & 1.91 & 0.49 & 2.74 & 0.34 & 30.39 & $<.001$ & 2.00 \\
\hline Competency-based education & 328 & 1.88 & 0.59 & 2.69 & 0.41 & 27.05 & $<.001$ & 1.62 \\
\hline Teaching methods and activities & 304 & 1.85 & 0.53 & 2.65 & 0.44 & 26.38 & $<.001$ & 1.65 \\
\hline Evaluation and assessment & 311 & 2.04 & 0.49 & 2.68 & 0.42 & 21.65 & $<.001$ & 1.41 \\
\hline Educational technology & 326 & 1.32 & 0.91 & 2.55 & 0.69 & 24.65 & $<.001$ & 1.54 \\
\hline
\end{tabular}

Note. Scale: $0=$ none, $1=$ low, $2=$ average, $3=$ high; low $\leq 1.5 ;<1.5$ average $<2.5 ;$ high $\geq 2.5$. The significance level for mean difference is at 0.05 .

\section{Conclusions}

Teachers tended to report a lower current knowledge/skills and a higher desired knowledge/skills in all 40 items related to curriculum and instruction. Educational technology was the lowest rated current skill area among six categories. Teachers seemed particularly interested in improving their knowledge and skills in the most common practices in teaching and learning. These areas were: lesson plan development, teaching material preparation, skills of lecturing and demonstrating, motivating student to learn, student assessment, and developing students' problem-solving skills. As teachers have more autonomy, they may see the importance of these practices in improving students learning.
Overall, teachers were very interested in upgrading their knowledge and skills related to curriculum and instruction, as their self-reported scores showed a significant difference between their current knowledge/skills level and desired knowledge/skills level. The results also revealed that teachers felt particularly inadequate in areas of educational technology and curriculum and innovative teaching. However, most teachers desired more training in educational technology, as they perceived that they had very limited expertise and skills in this area. Teachers might also see a great potential of using technology to improve the quality of teaching. In the past, teachers had a very limited use of technology in classrooms. Few teachers used overhead projectors and very few teachers have tried computer-aided instruction. 


\section{Implications and Recommendations}

Based on the results from this study, a need for teacher training and professional development is evident among the schools that were surveyed. Thus, policies and resources should be mobilized to tackle these issues.

It is strongly recommended that teachers be given the opportunities and support to attend training and professional development programs, which will likely increase their current knowledge base and enable them to successfully implement curriculum innovations.

Increasingly technology is used to overcome limitations and obstacles in teaching. With the rapid advancement and wide use of technology in education, it has the potential to help agricultural schools close the educational gap that exists between urban and rural schools. Therefore, educational technology should be put into teachers' training agenda.

Coherent and systematic policies and guidance should be formulated in teacher education and professional development activities. Resources, administrative and technical supports need to be provided to assist teachers in implementing reform initiatives. Young and beginning teachers may need more support and training than their older colleagues, especially in areas of teaching methods and curriculum planning and management. In addition, both pre-and in-service training needs to focus on the areas that teachers feel inadequate or where they never received formal training such as pedagogy, curriculum development, instructional methods, educational technology, and competency-based education. What is more, teacher education should be incorporated into higher education in agriculture to promote a systematic formulation of policies and action plans in teacher pre- and in-service training. Agricultural teachers need to have access to update their knowledge and skills annually through courses, seminars, and workshops that could provide pedagogical updates.
This study should send a strong signal to state and regional educational authorities in China regarding the need for professional development of teachers. The interest level of teachers wanting to improve their knowledge and skills is noteworthy. With all of the changes that are taking place in China, it is necessary for vocational agriculture to keep pace with changes in the industrial sector of society. China has one of the largest agricultural workforces in the world. With more than 60 percent of the people in China with direct agricultural production ties it is critical that the next generation of agriculturalist have improved education. Implementing the recommended changes noted in this study could be the first step toward fundamental and systematic changes in the system of vocational agricultural education in China.

\section{References}

Chen, X. A. (2000). A few thoughts on the reform and development of agricultural schools. The Journal of Agricultural Vocational Education (in Chinese). 36(2), 4-6.

Cochran, W. G. (1977). Sampling Techniques. New York: John Wiley and Sons, 72-88.

Cohen, J. (1988). Statistical power analysis for the behavioral sciences ( $2^{\text {nd }}$ edition). Hillsdale, NJ: Erlbaum.

Copa, G. H. (1992). A framework for the subject matter of vocational education. National Center for Research in Vocational Education, University of California at Berkeley, 1995 University Avenue, Suite 375, Berkeley, CA 94704.

Copa, G. H., \& Bentley, C. B. (1992). Vocational education. National Center for Research in Vocational Education, University of California at Berkeley, 1995 University Avenue, Suite 375, Berkeley, CA 94704. 
Erickson, H. L. (2001). Stirring the head, heart and soul: Redefining curriculum and instruction ( $2^{\text {nd }}$ edition.). Corwin Press, Inc., USA.

Kelly, A. V. (1982). The curriculum: Theory and practice. London, England: Harper and Row Publishers.

Ministry of Education (1998). Guidance in instruction reform of vocational education in $21^{\text {st }}$ century. Vocational Education, 1, Beijing, China: Ministry of Education.
Taylor, P. (2000). New perspective, new curricula: A case study of participatory curriculum development in forestry education in Vietnam. Paper prepared for the Forestry Education workshop, Vietnam, April 2000.

Weng, M. D. (1998). Reflection on the practice of competency-based education in agricultural schools (in Chinese). Journal of Instruction Research, 8, 1998. 